Out of Tune

How People Understand Social Exclusion at Concerts

Stijn Daenekindt, Ghent University and Erasmus University Rotterdam

stijn.daenekindt@ugent.be

ACCEPTED FOR PUBLICATION IN POETICS ON DECEMBER 5, 2018 


\title{
Out of Tune
}

\section{How People Understand Social Exclusion at Concerts}

\begin{abstract}
Previous work has studied the exclusive nature of legitimate cultural contexts, such as art museums and classical concerts. I offer a more comprehensive view by considering social exclusion in cultural settings varying in terms of legitimacy and by studying how people differ in their understanding of social exclusion (that is, criteria used to draw social boundaries demarcating certain cultural settings as inappropriate for some people). I scrutinize the centrality of modes of consumption in these understandings of social exclusion. Using survey data representative for the Flemish population $(n=3,144)$, I inductively analyse attitudes towards classical and pop/rock concerts. I uncover four understandings of social exclusion that are present with regard to both types of concerts. These understandings differ (a) in whether they stem from an insiders' or outsiders' perspective and (b) in how they use modes of consumption as criteria for social exclusion. Additionally, I find that people's understanding of social exclusion-i.e., which criteria people consider relevant for social exclusiondrives what cultural contexts they perceive as socially exclusive.
\end{abstract}

\section{Keywords}

Attitudes; Boundary drawing; Correlational Class Analysis (CCA); Distinction; Modes of consumption; Perception of social exclusion; Social boundaries; Symbolic boundaries; Taste. 
"Only those who exclude themselves are ever excluded."

(Bourdieu et al., 1991: 37)

\section{Introduction}

A core premise in the sociology of culture is that social judgements of taste are central to processes of social exclusion (e.g., Bourdieu, 1984; DiMaggio, 1987). Various studies report social exclusion in legitimate cultural settings, such as art museums, opera, classical concerts. With regard to art museums, for example, which are practically accessible to everybody, Bourdieu argues, "only those who exclude themselves are ever excluded" (Bourdieu et al., 1991: 37). Bourdieu associates this with a "reverential distancing" by the working classes, comprised of feelings of unworthiness, incompetence, and unease. Similarly, other studies argue that feelings of "not belonging" and estrangement are primary reasons why lower social strata are underrepresented in legitimate cultural settings (e.g., Dearn and Pitts, 2017; Zolberg, 1991; Warde, 2017).

The potential of taste for processes of social exclusion is central to the sociology of culture. However, the perspective advanced by empirical studies has been rather one-sided. Existing work generally focuses on how lower social strata individuals are excluded from legitimate cultural settings (see also: Jarness and Flemmen, 2017). This focus has yielded valuable insights, but has prevented the sociology of culture from achieving comprehensive insight into the reasons why people consider certain cultural contexts socially exclusive. Advancing our knowledge on this is crucial because the way people perceive cultural settings and whether or not they consider them socially exclusive is paramount for social exclusion. Indeed, judgements about suitability and taste constrain individuals' choice to attend certain cultural settings (cf. Warde, 2017: 211) and are central to shaping the socially exclusive nature of contexts.

To offer insight into how people understand social exclusion in cultural settings, I rely on studies on modes of consumption (e.g., Daenekindt and Roose, 2014; Friedman et al., 2015; Jarness, 2015; Schwarz, 2013). I study attitudes towards concerts and focus on whether people consider these settings 
socially exclusive. To scrutinize the way people understand social exclusion, I analyse how the perception of social exclusion relates to modes of consumption. Consider, for example, a strong (positive) association of the belief that a certain concert is socially exclusive with the belief that that concert requires an intellectual mode of consumption. This would indicate that individuals consider this concert socially exclusive because of their conviction that not everybody is capable of appropriating culture intellectually. By studying attitudes towards concerts, I study heterogeneity in people's understandings of social exclusion. An understanding of social exclusion does not refer only to the criteria people use to exclude others, but also to how those who are excluded understand their being excluded. I consider social exclusion in two cultural settings which differ in terms of legitimacy, i.e., classical concerts and pop/rock concerts. Hence, my analysis offers insight into how social exclusion is understood in different cultural settings and by individuals on different sides of social boundaries.

In my empirical analysis, I inductively uncover four different understandings of social exclusion. These understandings differ in (a) whether they stem from the perspective of outsiders or insiders in the cultural setting and (b) how they relate to modes of consumption. Interestingly, each understanding is present with regard to both classical and pop/rock concerts. Moreover, my analysis suggests that people's understanding of social exclusion-i.e., which criteria they consider relevant for social exclusion—drives what cultural contexts they perceive as socially exclusive.

\section{Social exclusion in cultural settings}

\subsection{Social boundaries and cultural settings}

In their key article, Lamont and Molnar (2002: 168) define symbolic boundaries as 'conceptual distinctions made by social actors to categorize objects, people, practices, and even time and space'. These boundaries do not necessarily relate to inequality and domination. Symbolic boundaries are a necessary but insufficient condition for the existence of social boundaries (Lamont, 1992; Lamont and Molnar, 2002). Only when symbolic boundaries become central in processes of social exclusion, they become social boundaries. 
Scholarship on symbolic and social boundaries exists in a variety of areas of research (for an overview see: Lamont and Molnar, 2002; Pachucki et al., 2007). One of these areas of research, in which this article is situated, is interested in the role of aesthetic considerations for social boundaries. This field argues that cultural preferences are status markers and, in a Weberian sense, improve the life chances of those who have legitimate cultural preferences. For example, the tastes people display in their search for a job affects their success in the labour market (Thomas, 2018). Because people are judged based on their tastes, tastes become criteria for drawing social boundaries.

Empirically grasping social boundary drawing based on aesthetic considerations is difficult as, in line with dominant norms of openness and tolerance, people instinctively downplay the existence of social exclusion. However, behind narratives of tolerance towards other people's lifestyles, there often lie marked feelings of hostility, superiority and snobbery (Jarness and Friedman, 2017). To bypass superficial accounts of tolerance that might conceal social boundary drawing, I differentiate between two social attitudes about concerts. The first one-i.e., "this concert excludes some people"—assesses whether people consider certain types of concerts as socially exclusive. It relates to how individuals perceive a cultural setting from a societal point of view and the way that setting relates to broader society (cf. Van Steen, 2012). Studying this attitude allows me to circumvent superficial accounts of tolerance because it does not include judgments of superiority or inferiority. Moreover, this attitude does not include information on whether or not the respondent classifies him/herself as somebody who is being excluded or as somebody who excludes others, and therefore does not provide the opportunity to expose the respondent as a cultural snob.

The second social attitude I consider pertains to how individuals view a cultural setting in relation to themselves. That is, is a cultural setting in line with the individual's preferences and does s/he regard the cultural setting as something for her/him? Disentangling the two social attitudes allows for a differentiation between individuals who consider a certain cultural setting as socially exclusive from an insider's versus an outsider's perspective.

Much research has addressed conventions, rules accepted without question, and considerable scripting of details of behaviour in legitimate cultural settings, such as art museums (Bourdieu et al., 
1991), classical music concerts (Dobson and Pitts, 2011), opera concerts (Benzecry, 2009), and jazz concerts (Burland and Pitts, 2012). Concert genres differ in contextually appropriate conventions including when to sing along, when to applaud, the dress code, and behaviour during non-musical moments (e.g., Benzecry, 2009; Burland and Pitts, 2012; Dobson and Pitts, 2011). The particularities of a cultural context generate the potential for social exclusion as they allow some to identify others as outsiders. The experiences of first-time classical concert attendees are enlightening in this respect, as these attendees describe discomfort, frustration, and a profound awareness of being different from other audience members (e.g., Dearn and Pitts, 2017). In contrast, seasoned audience members appreciate the unwritten codes and rules present at classical concerts, which make them feel at home (Benzecry, 2009). In this article, I study how context-specific conventions are used to draw social boundaries demarcating certain cultural settings as inappropriate for some people. Inspired by recent studies, I focus on modes of consumption as context-specific conventions.

\subsection{Modes of consumption}

Various authors have argued that the way people consume culture-rather than, or in addition to, what they consume-functions as a status marker (Daenekindt and Roose, 2014; Friedman et al., 2015; Peters et al., 2018; Jarness, 2015). These studies reveal different ways of appreciating cultural objects and find that individuals from higher social strata systematically apply other modes of consumption than individuals from lower social strata. Given this stratification, these studies conclude that modes of consumption function as status markers and have implications for social inequality. However, as Lamont argues, cultural differences do not automatically translate into domination (Lamont, 1992: 177; see also: Jarness and Friedman, 2017). Different modes of consumption may exist peacefully side-byside, and individuals may dislike certain modes of consumption without disliking the people applying it ('to each their own'). Therefore, the exact role of modes of consumption in social exclusion remains largely unclear. 
Modes of consumption can affect social exclusion as they may be observed by others and hence become criteria for social exclusion. For example, Schwarz (2013) argues that people "read" the way others consume culture. Similarly, Jarness (2018) posits that modes of consumption are observable by bystanders, and thus may play an important role in processes of social exclusion. In this way, people observing others' modes of consumption may use these modes as criteria for demarcating social boundaries. A perspective that acknowledges the role of self-exclusion provides an additional mechanism through which modes of consumption can affect social exclusion: people may exclude themselves because they think they lack the appropriate mode of consumption for certain forms of culture. So, even if modes of consumption are hardly observable by bystanders (cf. Daenekindt and Roose, 2014), modes of consumption can-via a sense of entitlement to consume certain forms of culture — affect social exclusion. Indeed, how people think certain forms of culture should be consumed can be used as a criterion for social exclusion. I consider the two distinct modes of consumption that dominate the focus of the sociology of culture - the intellectual mode and the hedonistic mode. These modes of consumption have been revealed in various cultural domains (e.g., films, music, art) and in both private and public consumption of culture (e.g., Daenekindt and Roose, 2013, 2014; Hanquinet et al., 2014; Jarness, 2015; Roose, 2008; Peters et al., 2018; Van Eijck, 2018).

The intellectual mode of consumption relates to the idea that appreciating certain forms of culture requires skills and competence to allow for an art-for-art's-sake approach. This argument is often used to explain the social patterning of cultural preferences: individuals from lower social strata are seen as incompetent at decoding legitimate culture and thus as unable to appreciate it (Bourdieu, 1984; Peterson, 1992). This competence-related reasoning and the idea that prior knowledge is needed strongly contrasts with a more hedonistic mode of consumption. The hedonistic approach resonates with the taste for necessity observed by Bourdieu (1984). People who do not perceive and appreciate stylistic features of cultural products - that is, those who do not apply the intellectual mode - apply a more functional approach to culture. These individuals consume cultural goods that fascinate them and allow them to escape and counterbalance the stress of everyday life. 
Traditionally, research has associated the intellectual mode of consumption with legitimate culture and the hedonistic mode with more popular forms of culture. However, recent work challenges the idea that modes of consumption are mapped in a one-to-one fashion with forms of culture (Daenekindt and Roose, 2014). For example, Bennett et al. (2009; see also Van Eijck, 2018) find that some people have a serious, intellectual approach to appreciating and consuming classical music, while others employ an "anti-intellectual" approach and appreciate classical music because they find it relaxing. Therefore, the intellectual and the hedonistic mode of consumption may be relevant with regard to both legitimate and more popular cultural settings.

\subsection{Different understandings of social exclusion}

To grasp the way people understand social exclusion, I analyse how the attitude that a specific type of concert is socially exclusive relates to attitudes on modes of consumption. For example, individuals may feel they do not belong in a certain cultural setting because they think they lack the appropriate skills and competence. Similarly, individuals frequenting a certain cultural setting may think that other individuals do not belong in that setting because they approach it in a contextually inappropriate antiintellectual and hedonistic manner.

I aim to inductively uncover these different understandings of social exclusion. Nonetheless, it is possible to formulate tentative expectations that may aid in interpreting the results. One expectation is that, in a cultural setting, insiders and outsiders may understand social exclusion differently. As research on ethnic relations stresses, social inclusion is a two-way process and complete inclusion occurs only when people "on both sides of the boundary" perceive inclusion (Alba and Nee, 2003: 11). Likewise, the social exclusion of individuals from lower social strata in legitimate cultural settings has two analytically distinct aspects: whether individuals from lower social strata experience exclusion and whether individuals from higher social strata believe that lower strata individuals do not belong in these settings. Therefore, it can be expected that insiders and outsiders will understand social exclusion differently. 
Similarly, how social exclusion is understood may be associated with a context's degree of legitimacy. Based on widely shared beliefs, classical concerts are, in contrast to pop/rock concerts, deemed more valuable and worthy of appreciation (e.g., Daenekindt, 2018). Because both concerts differ in terms of perceived legitimacy, differences can be expected in the way people think they should consume culture in both contexts. Sociology of culture routinely focuses on preferences for legitimate culture, which function as status markers and provide an individual with social advantages. In line with this, most studies assume that social exclusion is asymmetric and present only in legitimate cultural settings, such as art museums and classical concerts, and not in less legitimate cultural settings, such as heavy metal concerts. However, in localized settings, expressing affinities with and preferences for legitimate culture may actually function contra-productively and result in being excluded (e.g., DiMaggio, 1991). Therefore, individuals from higher social strata may be excluded in popular cultural settings. This would suggest that social exclusion is a symmetric process, rather than an asymmetric one. By considering cultural settings which vary in terms of legitimacy, my analysis can provide insights into the (a)symmetric nature of social boundary drawing.

\section{Analytical strategy}

My empirical strategy consists of two phases. In the first, I use Correlational Class Analysis (CCA) to inductively uncover shared understandings of social exclusion. CCA is a correlational-based extension of Relational Class Analysis (Boutyline, 2017; Goldberg, 2011). In addition to the two social attitudes on concerts, I include attitudes on the two modes of consumption. In contrast to traditional clustering techniques, CCA does not group individuals with similar attitudes. Instead, CCA clusters individuals who have similar relationships between attitudes, and thus clusters individuals who are "in agreement on the structures of relevance and opposition that make actions and symbols meaningful" (Goldberg, 2011: 1402).

[Figure 1 about here] 
Figure 1 depicts this, illustrating the attitudes of four fictional individuals towards, for example, classical concerts. Individuals A and B (left-hand panel) differ in their attitudes on classical concerts, yet the structure of their attitudes is identical. Individual A believes that classical concerts require an intellectual approach, and that they exclude some people; individual B does not believe that classical concerts require an intellectual approach and believes that classical concerts do not exclude people. This suggests that both individuals share an understanding of social exclusion: they consider classical concerts as socially exclusive (inclusive) because these concerts (do not) require an intellectual approach. Individuals C and D (right-hand panel) express an understanding of social exclusion in which a hedonistic mode of consumption seems paramount: classical concerts are considered exclusive because they require a hedonistic approach and because not everybody is willing/able to apply this approach.

In the second phase of the analysis, I study who considers which cultural contexts socially exclusive. People who assign a different meaning to social exclusion likely differ in which cultural settings they consider socially exclusive. Therefore, I regress the attitude on social exclusion on the different understandings of social exclusion and socio-demographic indicators. ${ }^{i}$ Here, I pay specific attention to educational level for two reasons. Research on modes of consumption finds that modes of consumption differ substantially between educational groups (Daenekindt and Roose, 2014; Jarness, 2015; Roose, 2008). Hence, educational groups likely differ in how they consider modes of consumption relevant for social exclusion. Moreover, previous research has convincingly demonstrated that education-more than, for example, occupation or income-strongly associates with cultural preferences and practices (Bourdieu, 1984; Bennett et al., 2009; Bryson, 1996). Therefore, individuals from different education levels approach cultural settings differently and may differ in which cultural contexts they consider socially exclusive. 


\section{Data and measures}

I use data from the Participatiesurvey 2009 (Lievens and Waege, 2011), which is based on a representative sample of the Flemish population, that is, the Dutch-speaking population of Belgium. The data were collected from 3,144 respondents by means of computer-assisted face-to-face interviews with a response rate of $68.0 \%$.

I studied attitudes about classical concerts and pop/rock concerts. I assessed these using the question "Irrespective of whether or not you have attended a lot of ['classical concerts'/‘pop or rock concerts'], what do you think about ['classical concerts'/"pop or rock concerts']?” A split-half design was used to limit the questionnaire. That is, based on random assignment, respondents were asked for their opinion on classical concerts ( $48.8 \%$ of the sample) or on pop/rock concerts (51.2\% of the sample). Responses were measured on 7-point bipolar scales. Table 1 presents the items that indicate a particular attitude towards concerts, which are based on pilot in-depth interviews.

[Table 1 about here]

Two social attitudes towards concerts are included. The first- "this excludes some people"assesses concerts from a societal point of view and thus measures whether or not the respondent considers the type of concert they evaluated as socially exclusive. ${ }^{\text {ii }}$ The second aspect pertains to the respondent's personal point of view about these concerts and is measured using the item "this is something specifically for me".

The next four items measure attitudes about modes of consumption. Items 3 and 4 capture attitudes on the intellectual mode of consuming and thus measure the extent to which respondents consider prior knowledge and concentration necessary to appreciate the type of concert they evaluated. The hedonistic dimension is measured using items that assess whether respondents consider concerts fascinating and relaxing (Items 5 and 6). 
The following socio-demographic variables are included in the regression analyses: gender (49.6\% females), age (mean $=49.2 ; \mathrm{SD}=16.1)$, and educational level. Educational level refers to the highest level of education that is successfully finished and is measured in three categories: no education or primary education (10.6\%), secondary education (54.8\%), and tertiary education (i.e., post-secondary education) (34.6\%). Next to these socio-demographic variables, the regression analyses also includes the respondent's understanding of social exclusion (cluster membership variable based on the CCA). I also control for the experience individuals have with both types of concerts. This was measured using questions assessing whether or not respondents attended a pop/rock concert (8.7\%) or a classical concert $(6.8 \%)$ in the previous six months.

\section{Analysis}

\subsection{Four distinct understandings of social exclusion}

The CCA was performed using the corclass package in R (Boutyline, 2016, 2017) and yielded four clusters/understandings. ${ }^{\text {iii }}$ To improve readability, I introduce labels for each cluster here and will clarify the choice for each of them later in the discussion of the results. The first cluster clearly aligns with how the literature generally reflects on social exclusion from cultural settings and is labelled 'reverential distancing' ( $22.9 \%$ of the sample). The second understanding is characterized by an absence of criteria for social exclusion. For a lack of a better term, I label the second cluster as 'alternative understanding' ( $37.5 \%$ of the sample). Because this understanding is the most difficult to interpret, and perhaps characterized by internal heterogeneity in terms of the way social exclusion is understood, the remainder of the analysis mostly focuses on the other three, more interpretable, clusters. The final two understandings of social exclusion are characterized by a clear aversion to a certain approach of culture. In the third understanding, an aversion to taking culture too seriously is central. This resonates with Bourdieu's ideas on cultural goodwill and, hence, I label this cluster as 'aversion to cultural goodwill' (19.6\% of the sample). The fourth understanding is characterized by an aversion 
to a relaxed and hedonistic approach to culture and is clearly situated in the traditional Bildungsideal. I label this cluster as 'aversion to hedonism' (20.1\% of the sample).

An obvious initial question is whether the different understandings of social exclusion are related to the type of concert the respondents evaluated. Table 2 presents the cross-tabulation of the four understandings and the two types of evaluated concerts. The presence of the four understandings with regard to classical concerts and pop/rock concerts indicates that people understand social exclusion similarly across both cultural settings.

[Table 2 about here]

The understandings do not differ from one another in the values on the included items, but in the relationships between the values on each item. Therefore, each understanding includes respondents scoring high on the item for social exclusion and individuals scoring low on this item (cf. Figure 1). Because the difference between the understandings consists of the position of the item for social exclusion with regard to the other items, I interpret the clusters by examining the bivariate correlations between the included items. This approach is in line with previous studies (e.g., Boutyline, 2017; Daenekindt, 2017; Daenekindt et al., 2017; DiMaggio et al., 2018; DiMaggio and Goldberg, 2018; Goldberg, 2011). Figure 2 and Figure 3 depict the correlational patterns of each understanding as networks. Nodes correspond to the items and lines represent the correlations between them. Solid lines represent positive correlations, while dashed lines represent negative correlations. The width and shade of the lines is proportional to the strength of the correlations, as wider and darker lines represent stronger correlations. Only significant correlations are shown $(p \leq .05)$. In addition to the network visualizations, Figures 2 and 3 also present the correlation matrices of each understanding (shading proportional to correlation strength). For the interpretation, the main point of interest is the position of the item assessing social exclusion (SE) with regard to the other items in each understanding. My interpretation 
focuses on the end of the spectrum where individuals consider concerts socially exclusive, which the label applied to each understanding reflects.

[Figure 2 about here]

\subsubsection{Reverential distancing}

A negative correlation between the items measuring personal appreciation (Me) and social exclusion (SE) characterizes the first understanding (-.73). That is, individuals considering a concert to be socially exclusive (high value on SE) do not consider this concert to be something for them (low value on Me). For example, people who argue that pop/rock concerts are not something for them also argue that these settings exclude some people. That is, they consider pop/rock concerts socially exclusive from the perspective of an outsider. Vice versa, individuals who do not consider a concert socially exclusive (low value on SE) consider this concert to be something for them. It is clear, then, that individuals with this understanding who consider concerts socially exclusive, do so from an outsiders' perspective.

The second aspect important to the interpretation of the understandings is how social exclusion is associated with the modes of consumption. The item for social exclusion (SE) is correlated positively with the two items related to the intellectual mode of consumption (.82 for Knw and .82 for Cnc). This indicates that individuals claiming that a particular concert type requires much concentration and prior knowledge argue that the concert excludes some people. In contrast, individuals who do not think that concerts require concentration and prior knowledge believe that these concerts do not exclude people. This suggests that individuals with this understanding believe that a certain cultural setting excludes some people because not everybody is able to apprehend culture intellectually. Clearly, this understanding is based on an intellectual approach to culture and displays an outsiders' perspective on social exclusion. 
This strongly resonates with Bourdieu's (1984) ideas on reverential distancing. Exclusion from cultural settings associates with feelings of incompetence and unworthiness: "[...] they feel 'out of place' and they keep a check on themselves, for fear of drawing attention to themselves by some unseemly remark' (Bourdieu et al., 1991: 51). Indeed, a fear of revealing a lack of knowledge and a lack of competence is central in this understanding of social exclusion.

\subsubsection{Alternative understanding}

In this understanding, social exclusion (SE) correlates negatively with a personal preference (Me) (.59). That is, like the first understanding, social exclusion is understood from an outsiders' perspective. Social exclusion correlates negatively with every item on modes of consumption. However, these negative correlations are very weak as the strongest correlation is -.24. Therefore, in this understanding, individuals who consider a cultural context socially exclusive do not attribute its exclusive nature to either the hedonistic or the intellectual mode of consumption. This residual cluster is the most difficult to interpret and does not clearly associate to ideas from the literature. Different interpretations are possible here. One possibility is that people in this cluster consider other modes of consumption to be relevant for social exclusion. Another possibility is that the criteria these people consider relevant for social exclusion are unrelated to modes of consumption.

[Figure 3 about here]

\subsubsection{Aversion to cultural goodwill}

In the third understanding, social exclusion (SE) is correlated positively with personal appreciation (Me). That is, people who consider a concert socially exclusive (high value on SE) consider this concert to be something for them (high value on Me). This indicates that this understanding of social exclusion stems from an insiders' perspective. Interestingly, this view of social exclusion is not associated with the conviction that certain concerts demand prior knowledge and concentration. That is, these insiders 
do not think that the concerts they prefer, and which they consider socially exclusive, demand an intellectual mode of consumption. In this understanding - in contrast to reverential distancingintellectual capacity and competence are not the reasons some cultural settings are viewed as socially exclusive. Instead, it considers certain settings as socially exclusive for those who do not approach culture in a hedonistic way. This is shown by the positive correlation between social exclusion (SE) and the hedonistic mode of consumption (.61 for Fsc and .68 for Rlx).

The finding that social exclusion aligns with an aversion to approaching culture too seriously is reminiscent of Bourdieu's ideas on cultural goodwill (Bourdieu, 1984). As aptly phrased by Wacquant (2001: 116), people whose taste is characterized by cultural goodwill "know what the legitimate symbolic goods are but they do not know how to consume them in the proper manner-with the ease and insouciance that comes from familial habituation." Instead, because they do not evaluate culture from a "pure," disinterested perspective, they are guided by a "concern to "understand" " and take culture too seriously (Bourdieu, 1984: 43).

\subsubsection{Aversion to hedonism}

A positive correlation between personal appreciation (Me) and the item for social exclusion (SE) characterizes the fourth understanding. This indicates that social exclusion is understood from an insiders' perspective. The intellectual mode of consumption ( $\mathrm{Cnc}$ and $\mathrm{Knw}$ ) is correlated positively with social exclusion (SE). The items assessing a hedonistic mode of consumption (Rlx and Fsc) are negatively correlated to all other items. This indicates that individuals adhering to this understanding consider concerts socially exclusive (and something for them) when the concerts require an intellectual approach and when they are not fascinating and not relaxing.

This resonates with the traditional Bildungsideal (e.g., Kolb, 2001; Schulze, 1995; Van Eijck and Knulst, 2005): consumption of "serious" culture is central to individuals' cultivation and attending cultural contexts is a valuable learning experience and vehicle for self-development. As argued by Benzecry and Collins (2014: 321), "[t]his is not necessarily the same thing as enjoying music; it is duty, even hard work." Individuals not subscribing to this traditional Bildungsideal and who approach 
culture too hedonistically are, according to this understanding, individuals who do not belong in certain cultural settings.

\subsection{Who considers concerts socially exclusive?}

Next, I analyse how the way people understand social exclusion relates to the extent to which individuals consider concerts socially exclusive. To gain insight into how people vary in how much they consider concerts socially exclusive, I fit regression models with the item "this excludes some people" as a dependent variable for classical concerts and for pop/rock concerts. So, this item is used twice in the regression analyses: once as the dependent variable, and once to create one of the independent variables (i.e., the cluster membership of the CCA). This does not make the analysis tautological as the CCA does not cluster individuals on the value of this item, but on the way that item relates to the other items included in the CCA.

For both types of concerts, I estimated three models. The first model (M1) includes only sociodemographic variables. The second model (M2) includes - in addition to the socio-demographic variables - the effect of the different understandings. This variable is based on the CCA clustering. The third model (M3) also includes the interaction between the different understandings and educational level. Not including this interaction could result in overlooking educational differences within each understanding. Comparing the models indicates that the third model is superior to the first model (classical concerts: $\mathrm{F}=9.88 ; p \leq .000$; pop/rock concerts: $\mathrm{F}=101.95 ; p<.000$ ) and to the second model (classical concerts: $\mathrm{F}=5.71 ; p \leq .000 ;$ pop/rock concerts: $\mathrm{F}=36.72 ; p<.000$ ).

[Table 3 about here]

Table 3 present the full tables, including all estimated coefficients. The main point of interest pertains to the coefficients of educational level, the different understandings of social exclusion, and to the interaction between them. The interaction between education and the understandings indicates that 
the effect of education depends on which understanding individuals adhere to. Figure 4 shows the interaction between the different understandings and educational level.

[Figure 4 about here]

As can be seen in Figure 4, the way people understand social exclusion relates to the extent to which individuals consider concerts socially exclusive. Interestingly, for both types of concerts there are people who consider concerts to be highly exclusive. However, with regard to pop/rock concerts there is less consensus. For example, higher educated individuals who understand social exclusion as reverential distancing do not consider pop/rock concerts to be socially exclusive. With regard to classical concerts, there is more agreement among all groups (that is combinations of educational levels and understandings) that classical concerts are socially exclusive.

No educational differences are found among those who have an alternative understanding of social exclusion and among those who understand exclusion as aversion to hedonism. However, there are educational differences within the two other understandings of social exclusion, i.e., reverential distancing and aversion to hedonism.

Reverential distancing. Among people who understand social exclusion as reverential distancing, the two lowest educated groups consider classical concerts more socially exclusive than the highest educated group does. Remember, reverential distancing stems from an outsiders' perspective on social exclusion and is based on an intellectual approach to music. Therefore, it makes sense that lower educated individuals view classical concerts as socially exclusive-understood as "excluding oneself"- because one lacks the necessary knowledge and competence. Interestingly, this is also the case with regard to pop/rock concerts. That is, lower educated individuals consider pop/rock concerts also socially exclusive based on the intellectual mode of consumption. So, especially among the lower educated groups, reverential distancing leads to perceiving cultural contexts as socially exclusive.

Aversion to cultural goodwill. Among people who understand social exclusion as aversion to cultural goodwill the educational pattern is reversed (compared to reverential distancing). In this understanding, 
higher educated individuals, compared to lower educated individuals, consider classical concerts more socially exclusive. Aversion to cultural goodwill stems from an insiders' understanding and is based on a hedonistic approach. Indeed, higher educated individuals consider classical concerts socially exclusive because not everybody is willing to consume the music hedonistically. Rather, what drives this understanding is an aversion to taking music too seriously. It makes sense that, within this understanding, especially higher educated individuals consider cultural settings to be exclusive as they approach art from an 'art-for-art's sake' perspective. Higher educated individuals consider an overly intellectual approach to culture an inappropriate mode of consumption and hence a legitimate means of excluding others. For pop/rock concerts, the educational differences within this understanding are not significant.

\section{Discussion and conclusion}

\subsection{Insiders' and outsiders' understandings}

Concerts genres differ in their scripts, conventions, and rituals, such as singing along, applauding, dancing, dress code, visual cues from the musicians, behaviour during non-musical moments, and so forth. Insiders and outsiders may differ in how they read and evaluate these particularities. Indeed, my analyses demonstrate clear differences in the way insiders and outsiders understand social exclusion. For example, people who understand exclusion as reverential distancing-an outsiders' understanding - consider an intellectual mode of consumption as an important criterion for social exclusion. However, people who understand exclusion as aversion to cultural goodwill—an insiders' understanding — clearly do not consider the intellectual approach a relevant criterion for social boundary drawing. The finding that some people consider a competence-related approach irrelevant for social exclusion is surprising, as previous research has assumed that competence-related thinking is paramount to social boundary drawing in cultural settings. However, Bourdieu (1984) stresses that people subconsciously employ the decoding skills and competence necessary to appreciate culture. Therefore, insiders may not be aware of the necessity of having the decoding skills, which they intuitively and 
routinely apply. This may be why they perceive social exclusion as unrelated to competence-related aspects and as more related to a hedonistic approach to culture. My analysis demonstrates that insiders and outsiders in a cultural setting understand social exclusion in that setting differently and that they differ in the criteria they consider relevant for drawing social boundaries.

\subsection{Social boundary drawing as a symmetric process}

The sociology of culture is divided on whether social exclusion based on aesthetic considerations is a symmetric or an asymmetric process (Lizardo and Skiles, 2016). Studies claiming asymmetry argue that legitimate culture operates as a criterion for social exclusion, but popular culture does not. These studies exclusively consider legitimate cultural settings-art museums, opera concerts, classical concerts, and so forth — and focus on how individuals not familiar with high culture feel out of place in these settings (e.g., Bourdieu et al., 1991; Dobson and Pitts, 2011; Benzecry, 2009; Benzecry and Collings, 2014; Zolberg, 1991). To contribute to this, I focussed on both legitimate and more popular cultural settings.

The presence of the four understandings with regard to classical concerts and pop/rock concerts indicates that people understand social exclusion similarly across cultural settings. This does not mean that everybody considers both cultural settings equally exclusive. There is clear variation in the extent people consider both types of concerts socially exclusive, and the combination of the way people understand social exclusion and their educational level appears central to understand this variation. However, both for classical concerts and pop/rock concerts there are people who consider these contexts socially exclusive. The finding that both cultural contexts, each with a different degree of legitimacy, are considered exclusive suggests that social boundary drawing operates symmetrically rather than asymmetrically.

Various authors view social exclusion as asymmetrical because they consider legitimate culture as more complex and superior to popular culture (Bourdieu, 1984). There are two flaws in this argument. First, according to this argument, the complexity of legitimate culture makes it inaccessible to lower 
social strata, while the simplicity of popular culture makes it accessible to everybody. Because of the asymmetry in complexity, only legitimate culture has the potential to generate feelings of incompetence, discomfort, and alienation in legitimate cultural contexts. Indeed, specific skills and competences are required to appreciate legitimate culture; however, this may also be true for popular culture. Popular cultural objects also have specific conventions and complexities that are inaccessible for those not possessing the appropriate cultural competences (Kuipers, 2006).

The argument that considers social boundary drawing as an asymmetric process because of legitimate culture's complexity has a second flaw. It rests on the assumption that competence-related aspects are the only possible criterion for social exclusion. However, as my analysis shows, some people also consider other criteria and/or consider competence-related criteria entirely irrelevant for drawing social boundaries.

The symmetric nature of social boundary drawing resonates with DiMaggio's (1991: 134; see also: Carter, 2003) distinction between cultural capital and cultural resources. Cultural capital refers to the symbolic mastery of generally prestigious culture, which affects life chances within a national population. Cultural resources, on the other hand, entail symbolic mastery of cultural goods that may yield status in local subgroups and in specific contexts. While these cultural resources do not immediately affect life chances in the Weberian sense, they may be associated with social exclusion in localized settings. For example, individuals lacking the cultural resources to behave appropriately in and to speak intelligently about popular cultural settings may be excluded in these settings (even though they may possess a lot of cultural capital). This aligns with Friedman and Kuipers' claim (2013: 191) that people from lower social strata do not blindly endorse the superiority of legitimate culture. Indeed, in contrast to Bourdieu's claim, individuals from lower social strata do not automatically lapse into reverential distancing.

\subsection{Considering social boundaries}

Several studies suggest that attendance to traditional highbrow events (such as classical concerts) has declined over time, while participation in the more popular, commercial culture increases (DiMaggio 
and Mukhtar, 2004; Roose and Daenekindt, 2015; Van Eijck and Knulst, 2005). Arts organisation are concerned with this decline and have made attempts to attract more (and younger) people. Previous research argues that 'practical considerations' (such as cost of tickets) cannot explain why people do not attend cultural setting, and that feelings of not belonging are central (e.g., Bourdieu et al., 1991; Dearn and Pitts, 2010; Kolb, 2001). While I do not study motives and barriers for attendance in this article, I find that modes of consumption are central to this feeling of 'out of tune'. That is, the way culture is consumed —or how people think that culture should be consumed—shapes social exclusion at cultural settings. This may be insightful for cultural policy and arts marketing. For example, arts organizations have been experimenting with post-performance lectures and discussions to connect audiences and performers. These interventions are usually dominated by experts to give the audience 'expert' insights (Heim, 2012; Pitts and Gross, 2017). An unintended side-effect of this approach may be that these interventions reinforce the idea that there is such a thing as a proper mode of consumption for a specific cultural product (cf. Hall, 1973), which may boost processes of social exclusion at cultural settings. Of course, this tentative reflection requires empirical analysis, and should be addressed by future research.

People differ in whether or not they consider particular cultural contexts socially exclusive. A recent body of work argues that in addition to what people consume, how people consume culture serves as a source of distinction (Daenekindt and Roose, 2014; Peters et al., 2018; Holt, 1998; Jarness, 2015; Schwarz, 2013). Following this thinking, I focused on modes of consumption and find different understandings of social exclusion as people differ in which mode of consumption they consider relevant for drawing social boundaries. Obviously, these modes of consumption do not constitute the only possible criteria. Other possible criteria may relate to, for example, looks and clothing style (cf. Jarness and Flemmen, 2017: 10). The modest number of criteria included in the analyses is the main limitation of this study. Nevertheless, my analyses demonstrate marked differences in how people understand social exclusion and indicate that modes of consumption play a crucial role in social boundary drawing. Moreover, these different understandings appear closely connected to whether or not people consider a certain cultural setting socially exclusive. This is important, because - to return 
to the opening quote - "only those who exclude themselves are ever excluded" (Bourdieu et al., 1991: 37). Indeed, whether or not people consider a setting socially exclusive plays a key role in processes of social exclusion.

\section{Endnotes}

${ }^{\text {i }}$ Conventional cluster analyses usually investigate the socio-demographic profiles of the found clusters, for example, by taking cluster membership as a dependent variable and various socio-demographic characteristics as independent variables. In relation to CCA/RCA, such analyses are misleading (Goldberg, 2011: 1419), as people sharing an understanding of social exclusion may have very different attitudes (for example, individuals A and B in Figure 1).

ii The Dutch version of this item is: "niet voor iedereen weggelegd"- "voor iedereen weggelegd" (Lievens and Waege, 2011: 66). In Dutch, this expression clearly includes a connotation of social exclusion and, hence, allows to measure social boundary drawing. This item does not easily translate to English. For example, I initially translated it to "this is for everybody"-"this is not for everybody". However, this translation may only relate to symbolic boundaries ('to each their own'), and does not necessarily relate to social boundary drawing (I am grateful to Reviewer II for noting this). Because of these translation difficulties, I opted to translate the item to "This does not exclude people"-"This excludes some people" which is not a literal translation, but captures the connotation of social exclusion which is embedded in the Dutch version.

iii Following Boutyline and Vaisey (2017: 1443) and Boutyline (2017: 382-383), I tested the CCA solution using the SEM-based multiple-group testing technique. Using SEM, I fit two models: a model with a single covariance matrix to describe the complete dataset and a model with four covariance matrices (based on the CCA partitioning) (basically this is Box's M-test for homogeneity of covariance matrices). Comparing both models demonstrates that the CCA-partitioned model is superior $\left(\chi^{2}=\right.$ 5402.6; $p<.001)$. This indicates that the four clusters are distinct in the way the attitudes are organized and justifies the partitioning of the data uncovered by CCA. 


\section{References}

Alba R, Nee V (2003) Remaking the American Mainstream: Assimilation and Contemporary Immigration. Cambridge, MA: Harvard University Press.

Bennett T, Savage M, Silva E, et al. (2009) Culture, Class, Distinction. London and New York: Routledge.

Benzecry C (2009) Becoming a fan: On the seductions of opera. Qualitative Sociology 32(2): 131-151.

Benzecry C, Collins R (2014) The high of cultural experience: Toward a microsociology of cultural consumption. Sociological Theory 32(4): 307-326.

Bourdieu P (1984) Distinction: A Social Critique of the Judgment of Taste. Cambridge, MA: Harvard University Press.

Bourdieu P, Darbel A, \& Schnapper D (1991) The Love of Art. European Art Museums and their Public. Cambridge: Polity Press.

Boutyline A (2016) corclass: Correlational Class Analysis. R package version 0.1.1. https://CRAN.Rproject.org/package $=$ corclass .

Boutyline A (2017) Improving the measurement of shared cultural schemas with correlational class analysis: theory and method. Sociological Science 4: 353-393.

Boutyline A, Vaisey S (2017) Belief network analysis: A relational approach to understanding the structure of attitudes. American Journal of Sociology 122(5): 1371-1447.

Bryson B (1996) Anything but heavy metal: Symbolic exclusion and musical dislikes. American Sociological Review 61(5): 884-899.

Burland K, Pitts S (2012) Rules and expectations of jazz gigs. Social Semiotics 22(5): 523-543.

Carter P (2003) "Black" cultural capital, status positioning, and schooling conflicts for low-income African American youth. Social Problems 50(1): 136-155.

Daenekindt S, Roose H (2013) A mise-en-scène of the shattered habitus: The effect of social mobility on aesthetic dispositions towards films. European Sociological Review 29(1), 48-59.

Daenekindt S, Roose H (2014) Ways of preferring: Distinction through the 'what' and the 'how' of cultural consumption. Journal of Consumer Culture, first published on October 10, 2014 as doi: $10.1177 / 1469540514553715$. 
Daenekindt S, De Koster W, \& Van der Waal J (2017) How people organise cultural attitudes: cultural belief systems and the populist radical right. West European Politics 40(4): 791-811.

Daenekindt S (2017) On the structure of dispositions. Transposability of and oppositions between aesthetic dispositions. Poetics 62: 43-52.

Daenekindt S (2018) High culture. In The Blackwell Encyclopedia of Sociology, edited by George Ritzer and Chris Rojek. DOI: 10.1002/9781405165518.wbeos1214.

Dearn L, Pitts S (2017) (Un)popular music and young audiences: Exploring the classical chamber music concert from the perspective of young adult listeners. Journal of Popular Music Education 1(1): 43-62.

DiMaggio P (1987) Classification in Art. American Sociological Review 52(4): 440-455.

DiMaggio P (1991) Social structure institutions and cultural goods: The case of the United States. Pp. 133-155 in Social Theory for a Changing Society, edited by P. Pierre Bourdieu and J. Coleman. Boulder: Westview Press.

DiMaggio P, Mukhtar T (2004) Arts participation as cultural capital in the United States, 1982-2002: Signs of decline? Poetics 32(2): 169-194.

DiMaggio P, Goldberg A (2018) Searching for Homo Economicus: Variation in Americans' Construals of and Attitudes toward Markets. European Journal of Sociology, 59(2): 151-189.

DiMaggio P, Sotoudeh R, Goldberg A, \& Shepherd H (2018) Culture out of attitudes: Relationality, population heterogeneity and attitudes toward science and religion in the US. Poetic, 68: 31-51.

Dobson M, Pitts S (2011) Classical cult or learning community? Exploring new audience members' social and musical responses to first-time concert attendance. Ethnomusicology Forum 20(3): 353-383.

Friedman S, Kuipers G. (2013) The divisive power of humour: Comedy, taste and symbolic boundaries. Cultural Sociology 7(2): 179-195.

Friedman S, Savage M, Hanquinet L, \& Miles A (2015) Cultural sociology and new forms of distinction. Poetics 53, 1-8.

Goldberg A (2011) Mapping shared understandings using relational class analysis: The case of the cultural omnivore reexamined. American Journal of Sociology 116(5): 1397-1436. 
Hanquinet L, Roose H, \& Savage M (2014) The eyes of the beholder: Aesthetic preferences and the remaking of cultural capital. Sociology 48(1): 111-132.

Hall S (1973) Encoding and Decoding in the Television Discourse. Birmingham: CCCS.

Heim C (2012) 'Argue with Us!': Audience Co-creation through Post-Performance Discussions. New Theatre Quarterly 28(2): 189-197.

Jarness V (2015) Modes of consumption: From 'what' to 'how' in cultural stratification research. Poetics 53: 65-79.

Jarness V (2018) Viewpoints and points of view: situating symbolic boundary drawing in social space. European Societies 20(3): 503-524.

Jarness V, Friedman S (2017) 'I'm not a snob, but...': Class boundaries and the downplaying of difference. Poetics 61: 14-25.

Jarness V, Flemmen M (2017) A struggle on two fronts: boundary drawing in the lower region of the social space and the symbolic market for 'down- to- earthness'. The British Journal of Sociology, DOI: 10.1111/1468-4446.12345.

Kolb B (2001) The effect of generational change on classical music concert attendance and orchestras' responses in the UK and US. Cultural Trends 11(41): 1-35.

Kuipers G (2006) Television and taste hierarchy: The case of Dutch television comedy. Media, Culture \& Society 28(3): 359-378.

Lamont M (1992) Money, Morals, and Manners: The Culture of the French and the American Uppermiddle Class. University of Chicago Press.

Lamont M, Molnár V (2002) The study of boundaries in the social sciences. Annual Review of Sociology 28(1): 167-195.

Lievens J, Waege H (2011) Participatie in Vlaanderen I. Basisgegevens van de Participatiesurvey 2009. Leuven/ Den Haag: Acco.

Lizardo O, Skiles S (2016) Cultural Objects as Prisms: Perceived Audience Composition of Musical Genres as a Resource for Social exclusion. Socius 2: 1-17.

Pachucki M, Pendergrass S, \& Lamont M (2007) Boundary processes: Recent theoretical developments and new contributions. Poetics 35(6): 331-351. 
Peterson R (1992) Understanding audience segmentation, from elite and mass to omnivore and univore. Poetics 21(4): 243-258.

Peters J, van Eijck K, \& Michael J (2018) Secretly Serious? Maintaining and Crossing Cultural Boundaries in the Karaoke Bar Through Ironic Consumption. Cultural Sociology 12(1): 58-74.

Pitts S, Gross J (2017) “Audience exchange”: cultivating peer-to-peer dialogue at unfamiliar arts events. Arts and the Market 7(1): 65-79.

Roose H (2008) Many-voiced or unisono? An inquiry into motives for attendance and aesthetic dispositions of the audience attending classical concerts. Acta Sociologica 51(3): 237-253.

Roose H, Daenekindt S (2015) Trends in cultural participation. In: Wright, JD (ed.) The International Encyclopedia of the Social and Behavioral Sciences, 2nd ed. Amsterdam: Elsevier.

Schulze G (1995) Die Erlebnisgesellschaft: Kultursoziologie der Gegenwart. Frankfurt/New York: Campus Verlag.

Schwarz O (2013) Bending forward, one step backward: On the sociology of tasting techniques. Cultural Sociology 7(4): 415-430.

Thomas K (2018) The Labor Market Value of Taste: An Experimental Study of Class Bias in US Employment. Sociological Science 5: 562-595.

Van Eijck K, Knulst W (2005) No more need for snobbism: Highbrow cultural participation in a taste democracy. European Sociological Review 21(5): 513-528.

Van Eijck K (2018) A classic experiment. How does attendance affect the attitudes and beliefs of Dutch non-visitors of classical music concerts? In S. Dorin (Ed.), Déchiffrer les Publics de la Musique Classique: Perspectives Comparatives, Historiques et Sociologiques (pp. 93-111). Paris: Editions des archives contemporaines.

Van Steen A (2012) Hoe wij over Kunst en Cultuur denken: een Sociologisch Onderzoek naar Verschillen in Percepties en Betekenissen van Kunst en Cultuur in Vlaanderen. $\mathrm{PhD}$ thesis, Ghent University.

Wacquant L (2001) Durkheim and Bourdieu: the common plinth and its cracks. The Sociological Review 49(S1): 105-119.

Warde A (2017) Consumption: A Sociological Analysis. London: Palgrave Macmillan. 
Zolberg V (1991) Barrier or leveler? The case of the art museum. In Cultivating differences: Symbolic boundaries and the making of inequality, edited by M. Lamont, and M. Fournier. Chicago: University of Chicago Press. 
Figure 1. Two illustrative representations of social exclusion at concerts.
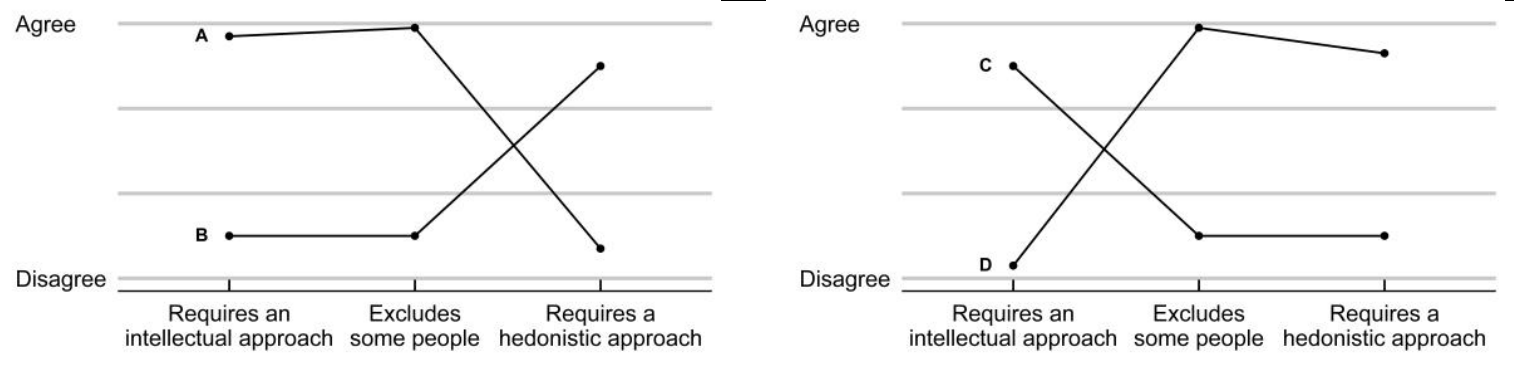
Reverential distancing
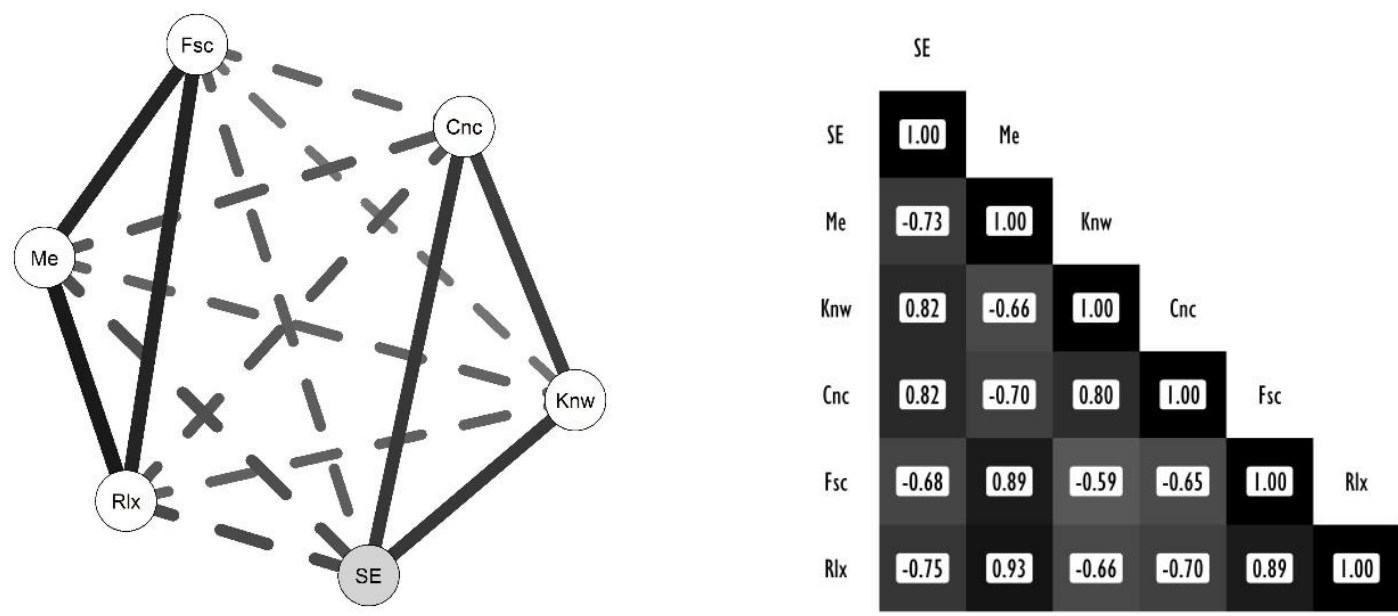

Alternative understanding
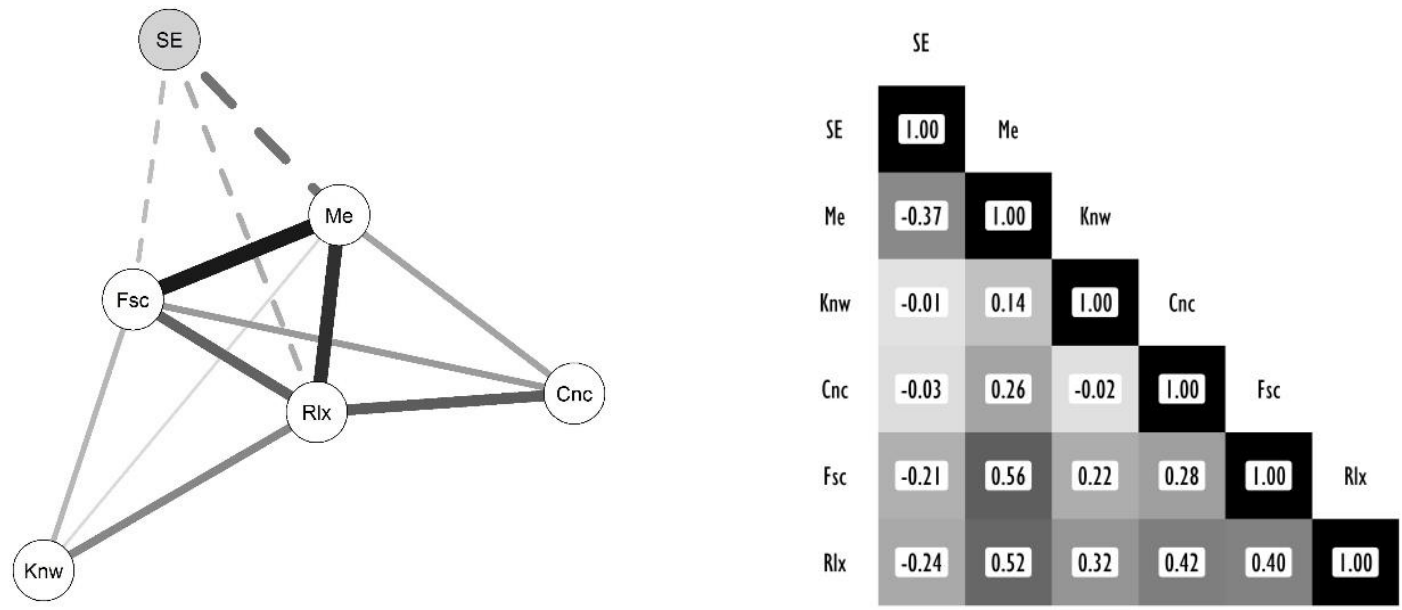

Labels: SE "This excludes some people"; Me "This is something specifically for me"; Knw "You have to know a lot about it"; Cnc "It demands a lot of concentration"; Fsc "Fascinating"; Rlx "Definitely relaxing". 
Figure 3. The two insiders' understandings of social exclusion.

Aversion to cultural goodwill
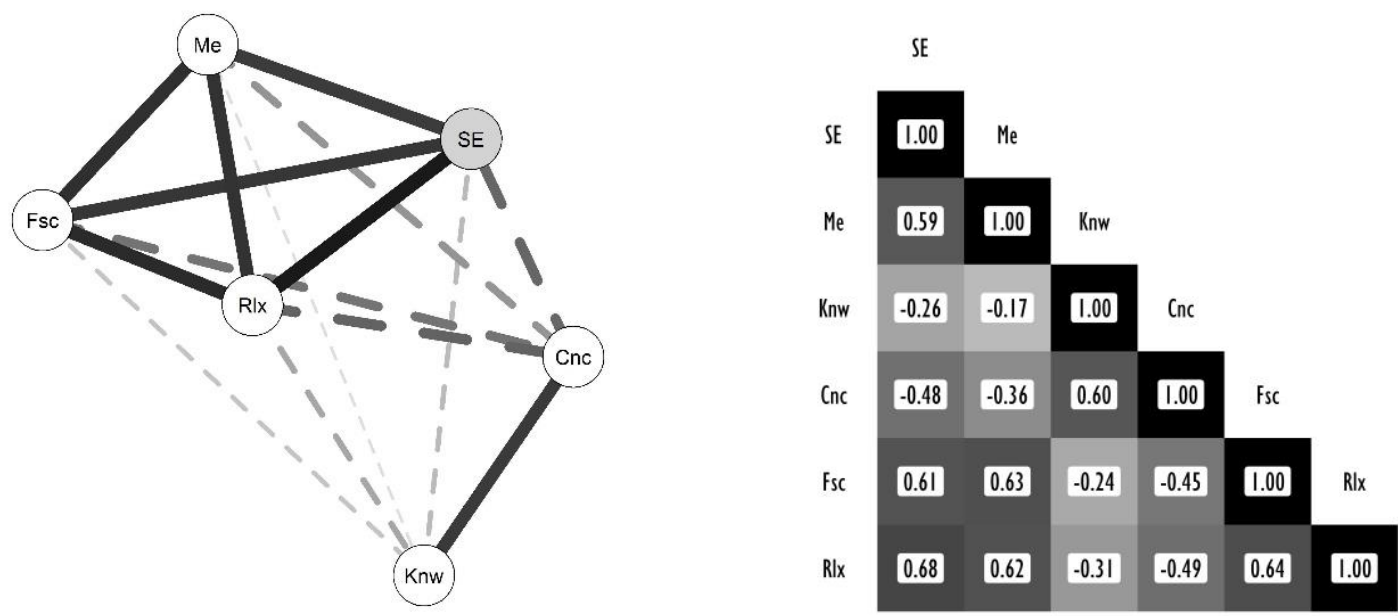

Aversion to hedonism
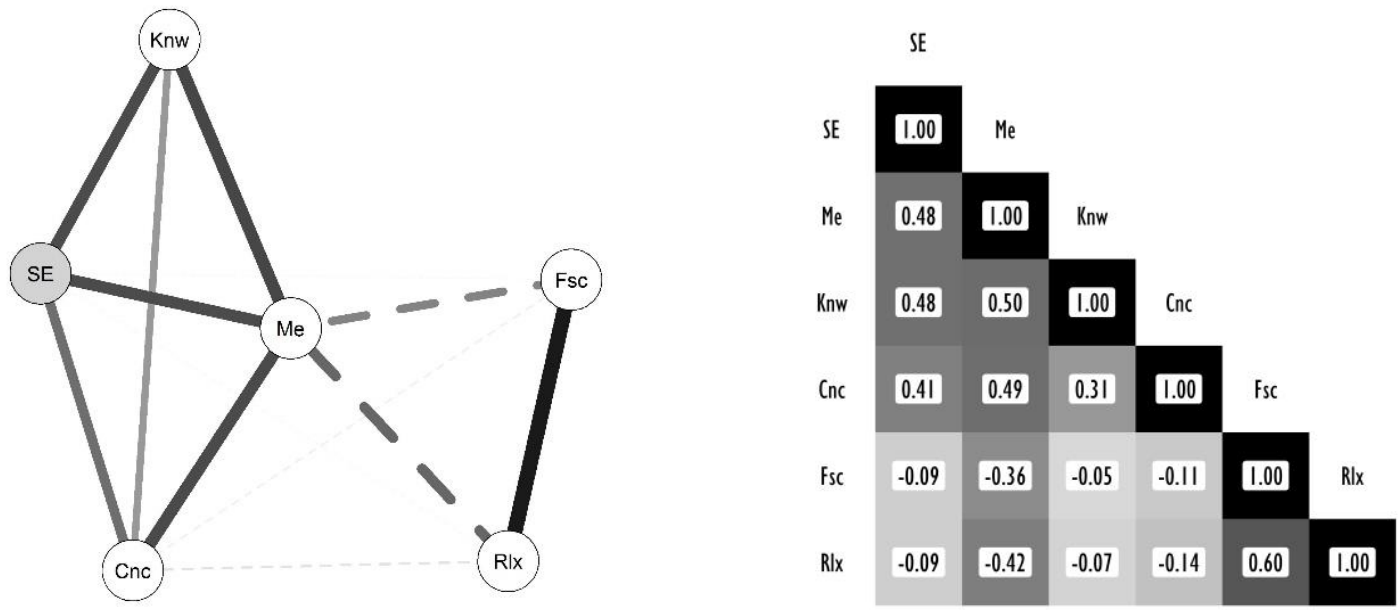

Labels: SE "This excludes some people"; Me "This is something specifically for me"; Knw "You have to know a lot about it"; Cnc "It demands a lot of concentration"; Fsc "Fascinating"; Rlx "Definitely relaxing". 
Figure 4. The interaction between the four understandings of social exclusion and educational level.

Classical concerts

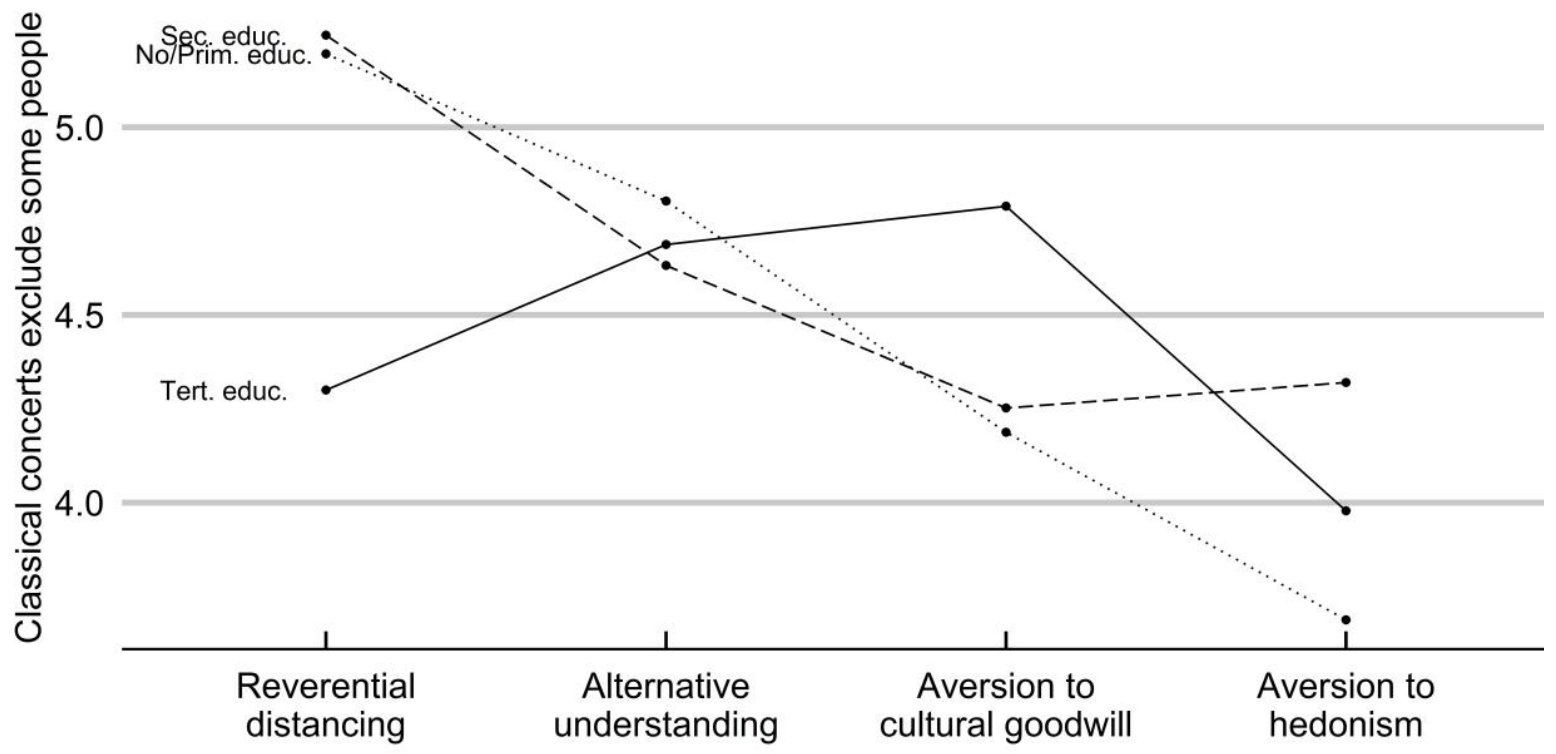

Pop/rock concerts

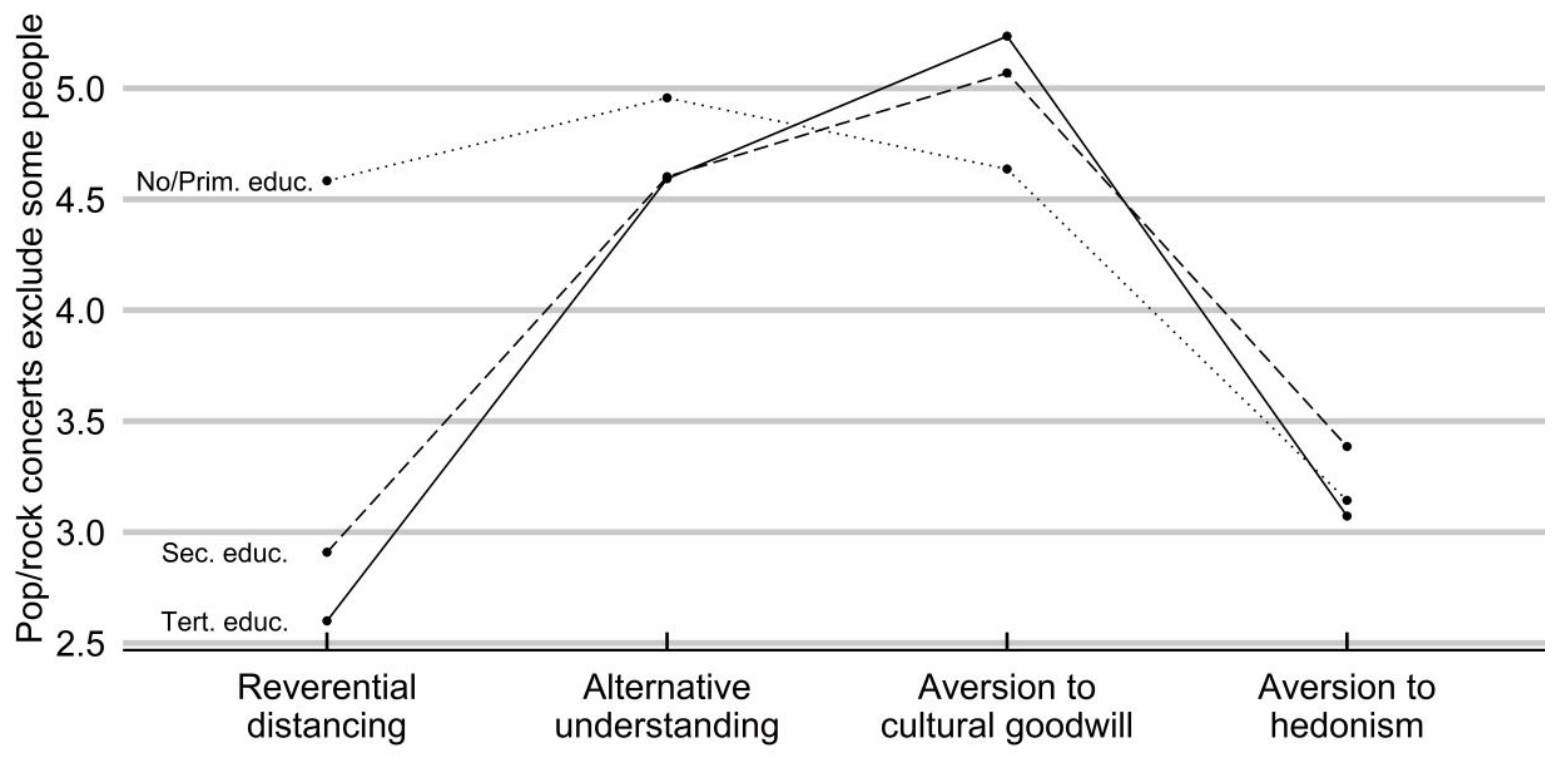


Table 1. Items (7-point bipolar scales) included in the split-half design to assess attitudes on classical concerts and pop/rock concerts.

\begin{tabular}{ll}
\hline Item & Label \\
\hline Social & SE \\
1. "This does not exclude people" - "This excludes some people"ii & Me \\
2. "This has nothing at all for me" - "This is something specifically for me" & Knw \\
Intellectual & Cnc \\
3. "You don't have to know anything about it" - "You have to know a lot about it" \\
4. "Attending requires little concentration" - "Attending requires a lot of concentration" \\
$\begin{array}{l}\text { Hedonistic } \\
\text { 5. "Boring" - "Fascinating" }\end{array}$ \\
6. "Not relaxing at all" - "Very relaxing" & Fsc \\
\hline
\end{tabular}

Original wording: "Whether or not you have attended a lot of ['classical concerts'/"pop or rock concerts'], what do you think about ['classical concerts'/‘pop or rock concerts']?” (random assignment). 
Table 2. Cross-tabulation of the understandings of social exclusion and evaluated concert (row percentages).

\begin{tabular}{lcc}
\hline & Classical concert & Pop/rock concert \\
\hline I. Reverential distancing & $46.8 \%$ & $53.2 \%$ \\
II. Alternative understanding & $56.2 \%$ & $43.8 \%$ \\
III. Aversion to cultural goodwill & $41.2 \%$ & $58.8 \%$ \\
IV. Aversion to hedonism & $54.8 \%$ & $45.2 \%$ \\
Total & & \\
\hline
\end{tabular}


Table 3. Regression analysis predicting 'this excludes some people' (standard errors are in parentheses).

\begin{tabular}{|c|c|c|c|c|c|c|}
\hline & \multicolumn{3}{|c|}{ Classical concerts } & \multicolumn{3}{|c|}{ Pop/rock concerts } \\
\hline & M1 & M2 & M3 & M1 & M2 & M3 \\
\hline Intercept & $\begin{array}{c}5.03^{* * *} \\
(.29)\end{array}$ & $\begin{array}{c}5.36 \text { *** } \\
(.30)\end{array}$ & $\begin{array}{c}5.55^{* * *} \\
(.36)\end{array}$ & $\begin{array}{c}3.44^{* * *} \\
(.31)\end{array}$ & $\begin{array}{c}2.49 * * * \\
(.29)\end{array}$ & $\begin{array}{c}3.64 \text { *** } \\
(.43)\end{array}$ \\
\hline Gender (male) & $\begin{array}{l}-.21^{*} \\
(.11)\end{array}$ & $\begin{array}{l}-.23^{*} \\
(.10)\end{array}$ & $\begin{array}{l}-.23^{*} \\
(.10)\end{array}$ & $\begin{array}{c}-.38^{* * *} \\
(.11)\end{array}$ & $\begin{array}{l}-.31^{* *} \\
(.10)\end{array}$ & $\begin{array}{c}-.30 * * \\
(.10)\end{array}$ \\
\hline Age & $\begin{array}{l}-.00 \\
(.00)\end{array}$ & $\begin{array}{l}-.00 \\
(.00)\end{array}$ & $\begin{array}{l}-.00 \\
(.00)\end{array}$ & $\begin{array}{c}.02^{* * *} \\
(.00)\end{array}$ & $\begin{array}{l}.02^{* * *} \\
(.00)\end{array}$ & $\begin{array}{c}.02 \text { *** } \\
(.00)\end{array}$ \\
\hline Attendance classical concerts & $\begin{array}{l}-.27 \\
(.21)\end{array}$ & $\begin{array}{l}-.24 \\
(.20)\end{array}$ & $\begin{array}{l}-.28 \\
(.20)\end{array}$ & - & - & - \\
\hline Attendance pop/rock concerts & - & - & - & $\begin{array}{l}-.14 \\
(.20)\end{array}$ & $\begin{array}{l}-.05 \\
(.18)\end{array}$ & $\begin{array}{l}-.03 \\
(.18)\end{array}$ \\
\hline Education & & & & & & \\
\hline No or primary & - & - & - & - & - & - \\
\hline Secondary & $\begin{array}{l}-.10 \\
(.18)\end{array}$ & $\begin{array}{l}-.02 \\
(.18)\end{array}$ & $\begin{array}{l}-.00 \\
(.31)\end{array}$ & $\begin{array}{l}-.13 \\
(.20)\end{array}$ & $\begin{array}{l}-.12 \\
(.18)\end{array}$ & $\begin{array}{c}-1.32 \text { *** } \\
(.39)\end{array}$ \\
\hline Tertiary & $\begin{array}{l}-.28 \\
(.20)\end{array}$ & $\begin{array}{l}-.15 \\
(.20)\end{array}$ & $\begin{array}{l}-.94 \text { ** } \\
(.35)\end{array}$ & $\begin{array}{l}-.05 \\
(.21)\end{array}$ & $\begin{array}{l}-.19 \\
(.19)\end{array}$ & $\begin{array}{c}-1.55^{* * *} \\
(.41)\end{array}$ \\
\hline $\begin{array}{l}\text { Understanding } \\
\text { I. Reverential distancing }\end{array}$ & & - & - & & - & - \\
\hline II. Alternative understanding & & $\begin{array}{l}-.34 \text { * } \\
(.14)\end{array}$ & $\begin{array}{l}-.44 \\
(.36)\end{array}$ & & $\begin{array}{l}1.56 \text { * } \\
(.14)\end{array}$ & $\begin{array}{c}.39 \\
(.42)\end{array}$ \\
\hline III. Aversion to cultural goodwill & & $\begin{array}{l}-.53^{* *} \\
(.17)\end{array}$ & $\begin{array}{l}-1.00 \\
(.52)\end{array}$ & & $\begin{array}{l}2.2^{*} \\
(.15)\end{array}$ & $\begin{array}{l}-.00 \\
(.64)\end{array}$ \\
\hline IV. Aversion to hedonism & & $\begin{array}{c}-.86 \text { *** } \\
(.16)\end{array}$ & $\begin{array}{c}-1.56 \text { ** } \\
(.52)\end{array}$ & & $\begin{array}{c}.26 \\
(.15)\end{array}$ & $\begin{array}{c}-1.42 \text { ** } \\
(.49)\end{array}$ \\
\hline $\begin{array}{l}\text { Understanding x Education } \\
\text { I x Secondary }\end{array}$ & & & - & & & - \\
\hline II x Secondary & & & $\begin{array}{l}-.19 \\
(.40)\end{array}$ & & & $\begin{array}{l}1.18 \text { ** } \\
(.46)\end{array}$ \\
\hline III x Secondary & & & $\begin{array}{l}-.00 \\
(.57)\end{array}$ & & & $\begin{array}{l}2.18^{* *} \\
(.68)\end{array}$ \\
\hline IV x Secondary & & & $\begin{array}{c}.64 \\
(.56)\end{array}$ & & & $\begin{array}{c}1.87^{* * *} \\
(.53)\end{array}$ \\
\hline I x Tertiary & & & - & & & - \\
\hline II x Tertiary & & & $\begin{array}{l}.82 \\
(.44)\end{array}$ & & & $\begin{array}{l}1.44^{* *} \\
(.48)\end{array}$ \\
\hline III x Tertiary & & & $\begin{array}{l}1.49 * \\
(.60)\end{array}$ & & & $\begin{array}{c}2.58^{* * *} \\
(.69)\end{array}$ \\
\hline IV $x$ Tertiary & & & $\begin{array}{l}1.21 * \\
(.60)\end{array}$ & & & $\begin{array}{l}1.79 * * \\
(.55)\end{array}$ \\
\hline
\end{tabular}

